Regular Article

\title{
Processing and size range separation of pristine and magnetic poly(L-lactic acid) based microspheres for biomedical applications
}

\author{
D.M. Correia ${ }^{\mathrm{a}, \mathrm{b}, *, 1}$, V. Sencadas ${ }^{\mathrm{a}, \mathrm{c}, 1}$, C. Ribeiro ${ }^{\mathrm{a}, \mathrm{d}, *}$, P.M. Martins ${ }^{\mathrm{a}}$, P. Martins ${ }^{\mathrm{a}}$, F.M. Gama ${ }^{\mathrm{d}}$, \\ G. Botelho ${ }^{\mathrm{b}}$, S. Lanceros-Méndez ${ }^{\mathrm{a}, \mathrm{e}, \mathrm{f}}$ \\ ${ }^{a}$ Centro/Departamento de Física, Universidade do Minho, Campus de Gualtar, 4710-057 Braga, Portugal \\ ${ }^{\mathrm{b}}$ Centro/Departamento de Química, Universidade do Minho, Campus de Gualtar, 4710-057 Braga, Portugal \\ ' School of Mechanical, Materials and Mechatronics Engineering, University of Wollongong, Wollongong, NSW 2522, Australia \\ ${ }^{\mathrm{d}}$ CEB - Centre of Biological Engineering, University of Minho, Campus de Gualtar, 4710-057 Braga, Portugal \\ e BCMaterials, Parque Científico y Tecnológico de Bizkaia, 48160 Derio, Spain \\ ${ }_{\mathrm{f}}^{\mathrm{f}}$ IKERBASQUE, Basque Foundation for Science, Bilbao, Spain
}

\section{A R T I C L E I N F O}

\section{Article history:}

Received 18 March 2016

Revised 5 May 2016

Accepted 11 May 2016

Available online 11 May 2016

\section{Keywords:}

Biocompatibility

Poly(L-lactic acid) microspheres

Oil in water emulsion technique

Cell viability

Magnetic nanocomposites

\begin{abstract}
A B S T R A C T
Biodegradable poly(L-lactic acid) (PLLA) and PLLA/CoFe $\mathrm{O}_{4}$ magnetic microspheres with average sizes ranging between $0.16-3.9 \mu \mathrm{m}$ and $0.8-2.2 \mu \mathrm{m}$, respectively, were obtained by an oil-in-water emulsion method using poly(vinyl alcohol) (PVA) solution as the emulsifier agent. The separation of the microspheres in different size ranges was then performed by centrifugation and the colloidal stability assessed at different $\mathrm{pH}$ values. Neat PLLA spheres are more stable in alkaline environments when compared to magnetic microspheres, both types being stable for pHs higher than 4, resulting in a colloidal suspension. On the other hand, in acidic environments the microspheres tend to form aggregates. The neat PLLA microspheres show a degree of crystallinity of $40 \%$ whereas the composite ones are nearly amorphous (17\%). Finally, the biocompatibility was assessed by cell viability studies with MC3T3-E1 pre-osteoblast cells.
\end{abstract}

(c) 2016 Elsevier Inc. All rights reserved.
* Corresponding authors at: Centro/Departamento de Física, Universidade do Minho, Campus de Gualtar, 4710-057 Braga, Portugal.

E-mail address: cribeiro@fisica.uminho.pt (C. Ribeiro).

${ }^{1}$ Equal contribution.

\section{Introduction}

Smart polymer microspheres have received increasing attention for biomedical applications such as drug delivery systems and support for cell expansion and differentiation $[1,2]$. 
In particular, the production of piezoelectric microspheres has been already achieved [2]. Piezoelectric polymers can be used as a bioactive electromechanically responsive materials for improving tissue engineering strategies [3]. Studies reveal that electrical stimulation influences cell proliferation, differentiation and regeneration [2] both under static [4,5] and dynamic conditions [6]. These results show the potential of such materials for the development of a new generation of wireless electrically active scaffolds and structures for biomedical applications [2].

Magnetic nanoparticles and, in particular magnetostrictive ones, offer also strong application potential in the biomedical field, including drug delivery and biomolecular targeting, among others, triggered by external magnetic field [7]. These applications are based on the large surface area of the nanoparticles, good tissue diffusion and reduced dipole-dipole interaction [8]. When combined with the piezoelectric effect, magnetostrictive nanoparticles offer the possibility of developing magnetoelectric composites [9] that convert magnetic stimuli into electrical ones, leading to novel tissue engineering strategies $[6,10]$. In particular, cobalt ferrite magnetic particles have been explored for biomedical applications due to its large magnetostriction, high Curie temperature and effective anisotropy and moderate saturation magnetization, which can be taken to advantage both for tissue engineering and drug delivery applications [11]. However, they should be coated with organic or inorganic materials in order to ensure their biocompatibility, nontoxicity and colloidal stability [8].

One of the most used polymers for biomedical applications is poly(L-lactic acid) (PLLA), which is a biocompatible and biodegradable aliphatic synthetic polyester. PLLA is also piezoelectric and its electroactive properties have been successfully explored for technological applications, being the $\beta$-form the main responsible for the piezoelectric properties $[12,13]$.

PLLA microspheres can be produced by several physicochemical methods, including solvent extraction/evaporation from an emulsion, aggregation by $\mathrm{pH}$ adjustment or heat, coacervation (phase separation), interfacial polymerization, ionic gelation, electrospray and spray drying, among other techniques [2,14-16]. Emulsionsolvent evaporation method is perhaps the most commonly used one [17]. The main advantages of the emulsion-solvent extraction/evaporation method (oil in water $(\mathrm{O} / \mathrm{W})$ or water in oil $(\mathrm{W} /$ O) emulsions) is its simple implementation using a stirrer device, without high temperatures or phase separating agents. Further, it allows the control of the size of the spheres in the nanometer to micrometer range comparatively to other methods such as the electrospray method [18], which does not allow such a control of sphere size. It is to notice that the sphere size is important for biomedical applications such as tissue engineering and drug delivery, in the later the microspheres size influencing the release rate, due to the encapsulation efficiency [19].

In this process, a solution containing the polymer is emulsified in a non-solvent continuous phase, in the presence of a stabilizing agent, using a variety of physical methods such as homogenization and sonication [20]. PLLA microspheres of relatively small size and uniform size distribution can be obtained from an aqueous continuous phase containing poly(vinyl alcohol) (PVA) as stabilizer [20,21].

The potential for application of neat or composite PLLA microspheres has been demonstrated in the treatment of ocular pathologies, namely in regenerative medicine for retinal repair or related intraocular pathologies [14] and drug delivery [7,22-24].

Despite these interesting proofs of concept, a systematic study reporting the effect of the processing parameters on the overall microspheres physico-chemical properties as well as on the encapsulation efficiency and biocompatibility of composite spheres with magnetic nanoparticles is still lacking. In particular, the introduction of highly magnetostrictive nanoparticles, such as $\mathrm{CoFe}_{2} \mathrm{O}_{4}$, has not been reported. Thus, this work, reports on an effective method for the preparation of pristine and magnetic PLLA microspheres based on $\mathrm{CoFe}_{2} \mathrm{O}_{4}$ nanoparticles.

\section{Experimental section}

\subsection{Materials}

Poly(L-lactic acid) (PLLA) with an average molecular weight of 217.000-225.000 $\mathrm{g} \mathrm{mol}^{-1}$, (Purasorb PL18) and poly(vinyl alcohol) (PVA) with an average molecular weight of 13.000-23.000, 98\% hydrolyzed were supplied by Purac and Sigma Aldrich. Chloroform (CF, from Merck) was used for the dissolution of the polymer. $\mathrm{CoFe}_{2} \mathrm{O}_{4}$ nanoparticles were purchased from Nanoamor [25] with dimensions between 35 and $55 \mathrm{~nm}$, and used as received.

\subsection{Preparation of neat and magnetic PLLA microspheres}

PLLA was dissolved in chloroform (CF) to achieve a polymer concentration of $3 \%(\mathrm{w} / \mathrm{v})$. CF is commonly used to dissolve PLLA due to its ability to solubilize large amounts of polymer [26], and low miscibility with water, leading to a decrease of the amount of PVA adsorbed to the polymer-organic solvent-water interface [21].

The polymer solution was dissolved at room temperature under constant stirring until complete polymer dissolution. Then, the mixture was added into $0.5 \%(\mathrm{w} / \mathrm{v})$ PVA solution. Polymer and surfactant concentrations were selected based on previous works [27]. The emulsified suspension was mechanically stirred (RS lab) and in the same time the solvent was continuously evaporated overnight at room temperature. The resulting microspheres were washed with distilled water and isolated by centrifugations at either 1000, 2500 and 4000 rcf's, for 5, 10 and $15 \mathrm{~min}$, respectively. This procedure was repeated 5 times. Finally, polymer microspheres were freeze dried (Christ Alpha 2-4 LD Plus from BioBlock Scientific) for $48 \mathrm{~h}$. Magnetic microspheres were also prepared by the aforementioned method. In this case, after complete polymer dissolution, $10 \%(\mathrm{w} / \mathrm{w})$ of $\mathrm{CoFe}_{2} \mathrm{O}_{4}$ nanoparticles were added to the solution. The next steps were the same as used for neat microspheres preparation.

\subsection{Characterization of the PLLA microspheres}

The morphology of the microspheres was analyzed using a scanning electron microscope (SEM, Quanta 650, from FEI) with an accelerating voltage of $5 \mathrm{kV}$. The samples were previously coated with a thin gold layer using a sputter coating (Polaron, model SC502). The average diameter and distribution was calculated over approximately 60 microspheres using SEM images with $50,000 \times$ magnification and the ImageJ software.

Infrared measurements (FTIR) were performed at room temperature in a Jasco 4100 apparatus in attenuated total reflectance (ATR) mode from 4000 to $400 \mathrm{~cm}^{-1}$ using 64 scans with a resolution of $4 \mathrm{~cm}^{-1}$. Differential scanning calorimetry measurements (DSC) were performed in a Mettler Toledo 823e apparatus using a heating rate of $10^{\circ} \mathrm{C} \mathrm{min}{ }^{-1}$ under nitrogen purge. The degree of crystallinity of the PLLA microspheres was calculated by Eq. (1):

$\Delta X_{c}=\frac{\Delta H_{m}-\Delta H_{c c}}{\Delta H_{m}^{O}}$

where $\Delta H_{m}$ is the melting enthalpy, $\Delta H_{c c}$ the enthalpy of cold crystallization and $\Delta H_{m}^{O}$ represents the PLLA theoretical value of the melting enthalpy of a fully crystalline sample $\left(93.1 \mathrm{~J} \mathrm{~g}^{-1}\right)[28,29]$.

Dynamic light scattering (DLS) was used to obtain the average hydrodynamic size and size distribution of the microspheres. A Zetasizer NANO ZS-ZEN3600 (Malvern) was used and measurements were performed at $25^{\circ} \mathrm{C}$ using the appropriated sample dilution in ultrapure water to prevent multi scattering 
events. The average and standard deviation values for each sample were obtained from 6 measurements.

Zeta potential was used to obtain the surface charge of the microspheres with a Zetasizer NANO ZS-ZEN3600. The zeta potential of the PLLA microspheres was evaluated at different pHs $(2,4,7$ and 9). Solutions of $\mathrm{HCl}(1 \mathrm{M})$ and $\mathrm{NaOH}(1 \mathrm{M})$ were added to adjust the $\mathrm{pH}$. The average value and standard deviation for each sample was obtained from 6 measurements. According to Smoluchowski equation the zeta potential was determined from Eq. (2) [30]:

$\zeta=\frac{\Delta E}{\Delta P} \frac{\eta k}{\varepsilon \varepsilon_{0}}$

where $\zeta$ is the zeta potential, $\Delta \mathrm{E}$ and $\Delta \mathrm{P}$ are the streaming potential and the applied pressure, respectively, $\eta$ is the viscosity of the solution, $\mathrm{k}$ the conductivity of the solution, $\varepsilon$ and $\varepsilon_{0}$ are the permittivity of the test solution and free space $\left(8.85 \times 10^{-12} \mathrm{~F} \mathrm{~m}^{-1}\right)$, respectively.

The magnetic behavior of PLLA $/ \mathrm{CoFe}_{2} \mathrm{O}_{4}$ microspheres was evaluated using a vibrating sample magnetometer (VSM) to measure the difference in the magnetic response obtained with and without the application of a 220 Oe DC magnetic field. The magnetic $\mathrm{CoFe}_{2} \mathrm{O}_{4}$ filler content within the microspheres was determined by Eq. (3) [16]:

$$
\begin{aligned}
\mathrm{CoFe}_{2} \mathrm{O}_{4} \mathrm{wt} \% \text { microspheres }= & \frac{\text { Saturation magnetization }_{\text {microspheres }}}{60(\text { pure powder saturation magnetization })} \\
& \times 100
\end{aligned}
$$

\subsection{Cell culture}

MC3T3-E1 cells (Riken cell bank, Japan) were cultivated in Dulbeccós modified Eagle's medium (DMEM, Gibco) $1 \mathrm{~g} \mathrm{~L}^{-1}$ glucose containing 10\% Fetal Bovine Serum (FBS, Biochrom) and 1\% penicillin/streptomycin ( $\mathrm{P} / \mathrm{S}$, Biochrom) at $37{ }^{\circ} \mathrm{C}$ in a $5 \% \mathrm{CO}_{2}$ incubator.

For cell culture assays, approximately $3 \mathrm{mg}$ of dry PLLA microspheres (with and without magnetic nanoparticles) were placed in a $2 \mathrm{~mL}$ Eppendorf. For sterilization purposes, the microspheres were exposed to ultraviolet (UV) light for $1 \mathrm{~h}$ and washed 5 times with phosphate buffer saline (PBS) solution for $5 \mathrm{~min}$. After that, the microspheres were placed with DMEM without FBS overnight at $37{ }^{\circ} \mathrm{C}$ in a $5 \% \mathrm{CO}_{2}$ incubator.

For the cell viability assay, MC3T3-E1 pre-osteoblast cells were seeded at a density of $1.5 \times 10^{5}$ cells/Eppendorf with and without $($ control + ) microspheres up to $72 \mathrm{~h}$. Microspheres without cells were also used as negative control. To quantify the number of viable cell, 3-(4,5-dimethylthiazol-2-yl)-5-(3-carboxymethoxyphenyl)-2(4-sulfophenyl)-2H-tetrazolium (MTS, CellTiter 96-Aqueous one solution reagent, Promega) colorimetric method was used. In this assay, MTS is bioreduced by cells into a formazan product by dehydrogenase enzymes found in metabolically active cells. The absorbance of the formazan product measured at $490 \mathrm{~nm}$ is directly proportional to the viable cell number in cell culture. After $72 \mathrm{~h}$, the supernatant of each Eppendorf was removed and fresh medium containing MTS solution in a 1:5 ratio was added and incubated at $37{ }^{\circ} \mathrm{C}$ in a $5 \% \mathrm{CO}_{2}$ incubator. After $2 \mathrm{~h}$ of incubation, $100 \mu \mathrm{L}$ of each Eppendorf was transferred in triplicate to a 96-well plate and the optical density was measured at $490 \mathrm{~nm}$. Four measurements were performed for each sample.

\section{Results and discussion}

\subsection{Polymer morphology and size distribution}

Neat PLLA and magnetic microspheres were produced by an oil in water emulsion $(\mathrm{o} / \mathrm{w})$ using PVA as stabilizer in order to prevent the coalescence of the microspheres.

Pristine polymer microspheres show a smooth spherical surface, with a homogeneous shape, without concavities or distortions (Fig. 1a), with size distribution ranging between 50 and $400 \mathrm{~nm}$ with an average size of $160 \pm 62 \mathrm{~nm}$ (Fig. 1d), suggesting that the polymer solution was evenly dispersed in the aqueous phase,
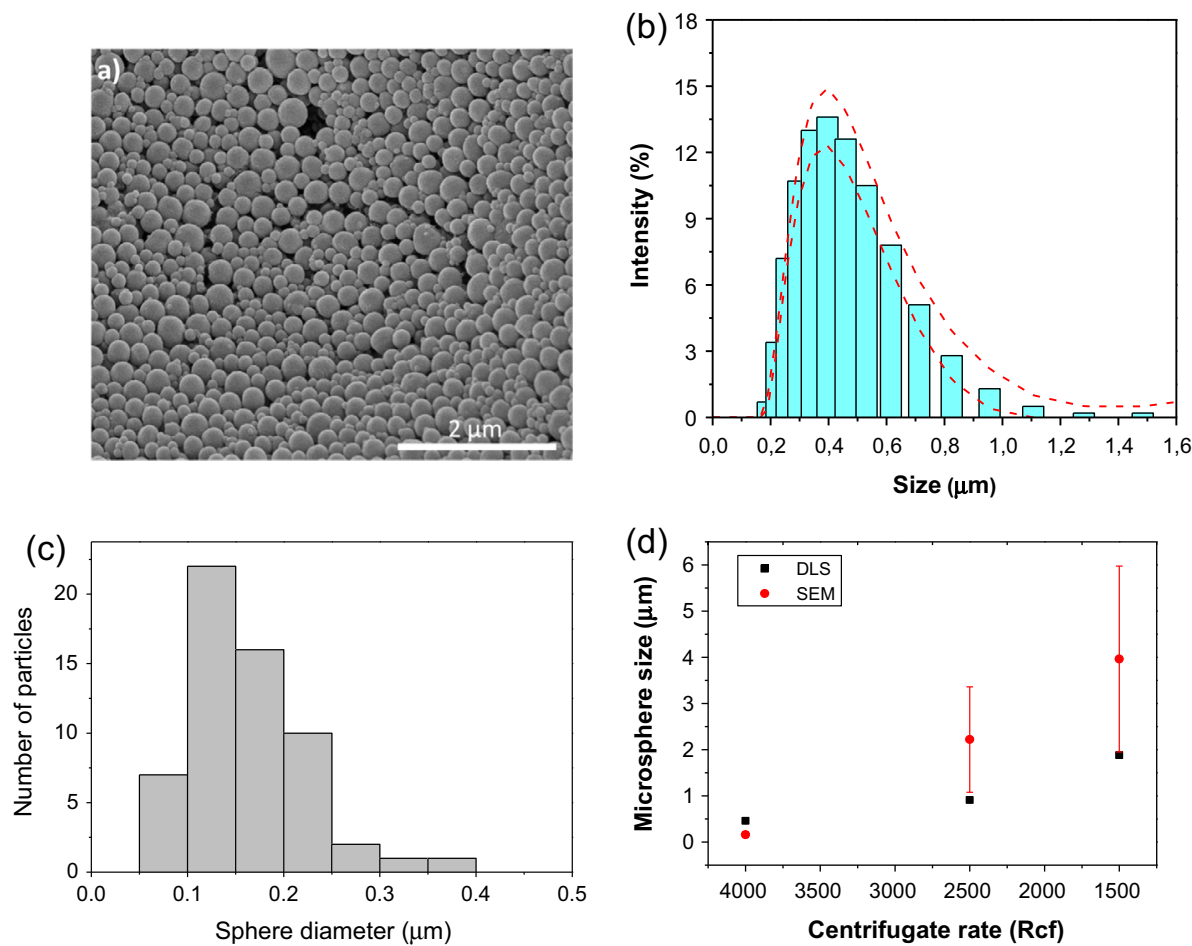

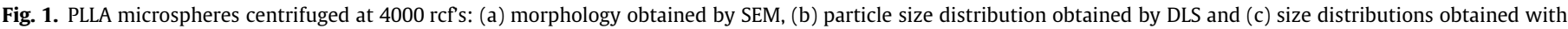

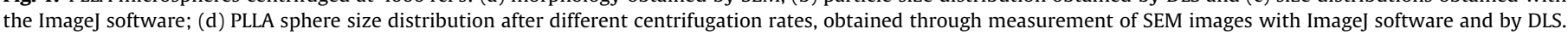


without precipitation of the solids [26,27]. Higher viscosities than the ones used in this work (see Section 2), creates difficulties in achieving small oil droplets homogeneously dispersed in the aqueous phase, leading to larger microspheres [27,31].

Centrifugation of the microspheres at different rates allows its separation by size (Fig. 1d). Thus, microspheres with average size ranging from $0.16 \pm 0.062 \mu \mathrm{m}$ up to $3.9 \pm 2.0 \mu \mathrm{m}$ were obtained at centrifugation rates varying from 1500 to $4000 \mathrm{rcf}$.

Dynamic light scattering allows the measurement of microspheres hydrodynamic size and distribution. The values obtained by DLS (size ranging from $1.9 \pm 0.039 \mu \mathrm{m}$ down to $0.46 \pm 0.013 \mu \mathrm{m}$ ) are different from the ones measured by SEM imaging (Fig. 1d), which is ascribed to factors affecting the hydrodynamic measurements such as the agglomeration of the spheres [32]. Comparing SEM and DLS, it can be observed that for 1500 and $2500 \mathrm{rcf}$, the DLS measurements show lower average sizes than SEM. These results indicate that dispersed microspheres, despite centrifuged, remain highly heterogeneous, which is also consistent with the high polydispersion index (higher than 0.5 ) obtained for the DLS assays. The larger particles found with SEM analysis are the ones that readily precipitate in aqueous medium, during the DLS analysis. On the other hand, for 4000 rcf's this trend is the opposite, as the SEM analysis allowed to estimate a lower average size with respect to the DLS values. This result indicates that higher centrifugation rates are efficient as size separation process, yielding a homogeneous sample. The slightly higher average size obtained for DLS when compared to SEM, is ascribed to agglomeration during the measurements [31].

With respect to the $\mathrm{CoFe}_{2} \mathrm{O}_{4} /$ PLLA microspheres (Fig. 2), also smooth microspheres were obtained, similar to the ones obtained for pristine PLLA (Fig. 1a). Again, centrifugation allows the separation of the spheres by size, from $2.2 \pm 0.60 \mu \mathrm{m}$, for the lowest centrifugation rate, to $0.87 \pm 0.35 \mu \mathrm{m}$ for the highest one (Fig. $2 \mathrm{~d}$ ). The nanocomposite microspheres show higher average sizes than pristine PLLA microspheres, for all centrifugation rates. These results are consistent with the presence of the magnetic core $\left(\mathrm{CoFe}_{2} \mathrm{O}_{4}\right.$ nanoparticles aggregates) inside the PLLA microspheres, yielding higher average diameters to the nanocomposite microspheres. Finally, it was not possible to obtain the hydrodynamic size due to higher aggregation and sedimentation of the heavier spheres during the measurements.

\subsection{Physico-chemical and thermal properties}

In order to evaluate possible chemical modifications in the structure of PLLA due to the processing procedure, a FTIR-ATR analysis was performed. Fig. 3a shows the FTIR spectra of the neat and composite PLLA microspheres. Table 1 shows the main absorption bands present in the microspheres spectrum. The absorption bands present in the $830-960 \mathrm{~cm}^{-1}$ region for the neat and magnetic microspheres are assigned to polymer backbone stretching and $\mathrm{CH}_{3}$ rocking [33]. The absorption band at $871 \mathrm{~cm}^{-1}$ is ascribed to $\mathrm{CH}_{3}$ rocking of the amorphous crystalline $\alpha$-phase. The presence of absorption bands at 921,955 and $1510 \mathrm{~cm}^{-1}$ assigned as the coupling of the $\mathrm{C}-\mathrm{C}$ backbone stretching with the $\mathrm{CH}_{3}$ rocking mode, indicating that neat PLLA microspheres crystallize into the $\alpha$-form [28].

The absence of the absorption bands at 920 and $1510 \mathrm{~cm}^{-1}$ in magnetic PLLA microspheres indicate that the microspheres are probably in the amorphous state, as it will be confirmed later by DSC. The vibrational assignments in the region between 1000 and $1500 \mathrm{~cm}^{-1}$ are $\mathrm{CH}, \mathrm{CH}_{3}$ and $\mathrm{C}-\mathrm{O}-\mathrm{C}$ stretching bands characteristics of the $\alpha$ and $\alpha^{\prime}$ forms. The band at $\sim 1451 \mathrm{~cm}^{-1}$ is assigned to the asymmetric deformation mode of $\mathrm{CH}_{3}$. The region of $1300-$ $1000 \mathrm{~cm}^{-1}$ is mainly related to the $\mathrm{C}-\mathrm{O}-\mathrm{C}$ stretching vibrations and to $\mathrm{C}-\mathrm{O}-\mathrm{C}$ asymmetric vibrations linked with asymmetric $\mathrm{CH}_{3}$ rocking vibrations [33].

Finally, the strong band at $1750 \mathrm{~cm}^{-1}$ identifies the stretching vibration of ester carbonyl $(\mathrm{C}=0)$. At $1080 \mathrm{~cm}^{-1}$ and the weak band at $1450 \mathrm{~cm}^{-1}$ corresponds to the stretching vibration of the methyl group $(\mathrm{C}-\mathrm{H})$ [34]. Neither modes are totally suppressed, nor do new modes seem to appear in neat and magnetic microspheres due to the emulsification process. Furthermore, no PVA residues were noticed in the microspheres FTIR spectra.
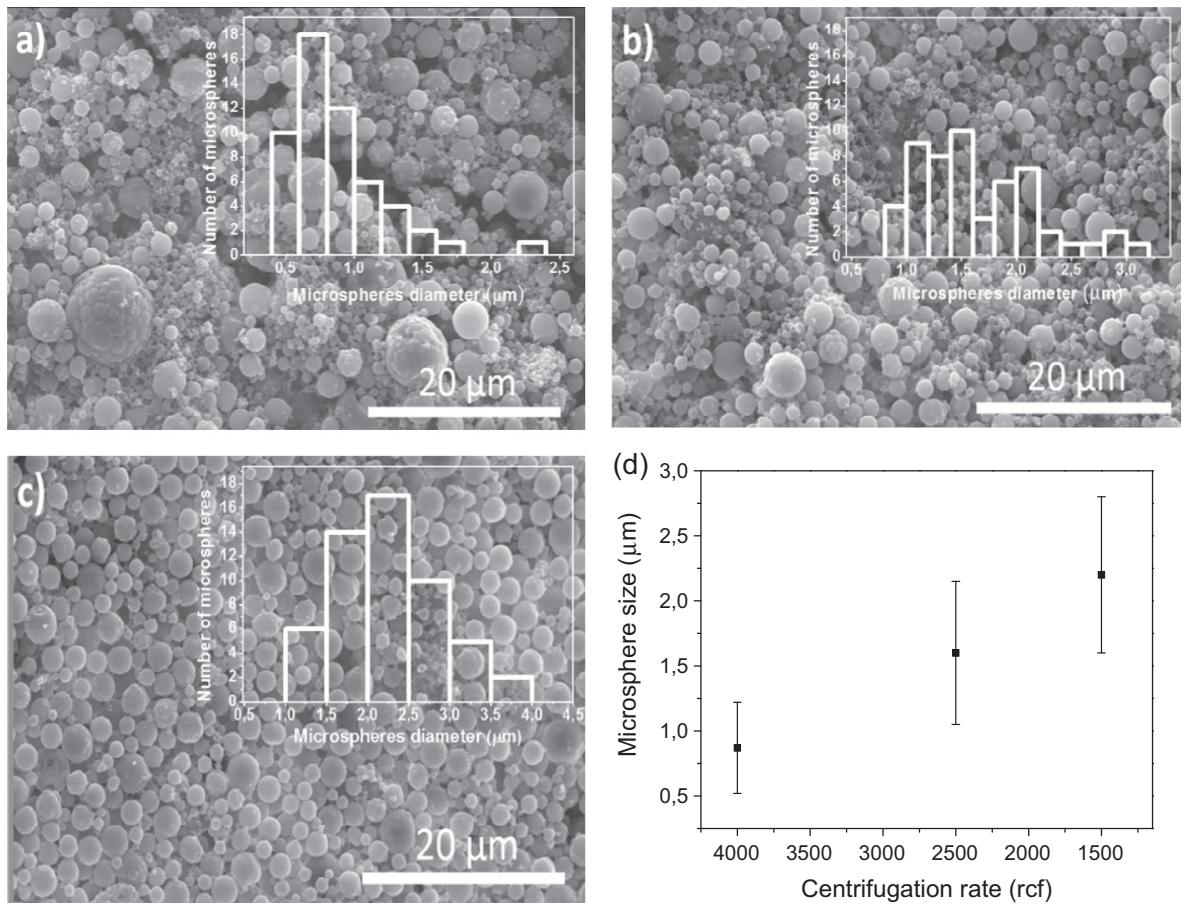

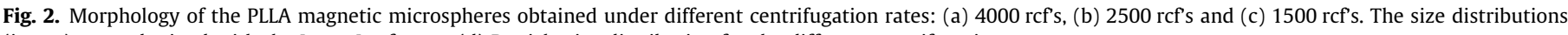
(insets) were obtained with the ImageJ software. (d) Particle size distribution for the different centrifugation rates. 

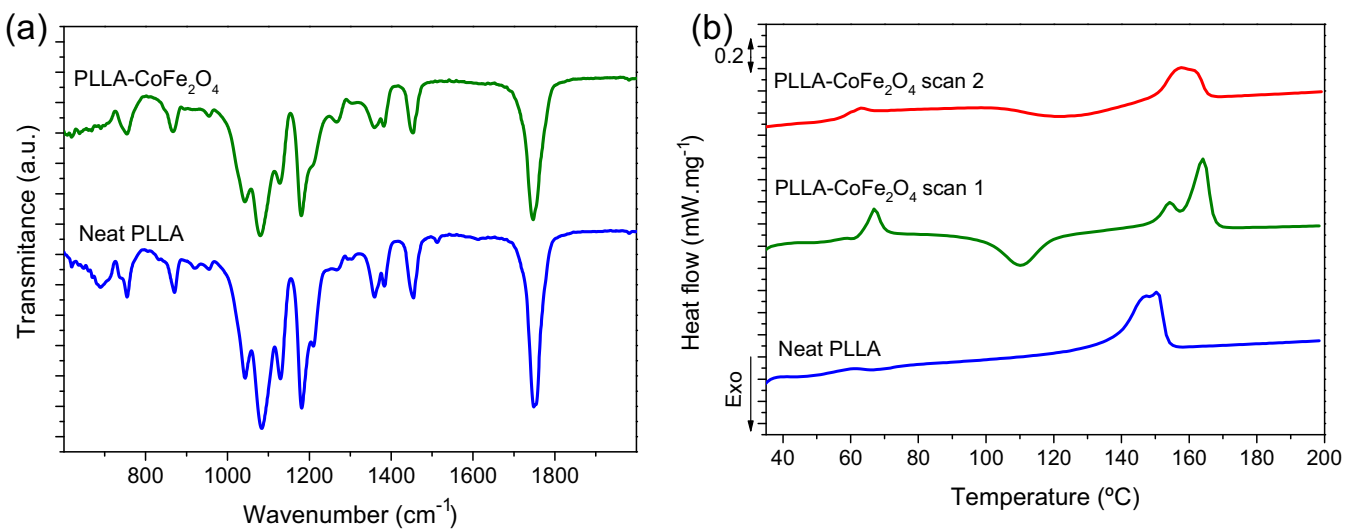

Fig. 3. (a) FTIR spectra and (b) DSC scans obtained for PLLA and $\mathrm{CoFe}_{2} \mathrm{O}_{4} /$ PLLA microspheres.

Table 1

Characteristic FTIR absorption bands and assignments for neat and magnetic PLLA microspheres.

\begin{tabular}{cl}
\hline $\begin{array}{l}\text { Wavenumber } \\
\left(\mathrm{cm}^{-1}\right)\end{array}$ & Absorption bands \\
\hline 871 & $\mathrm{CH}_{3}$ rocking \\
921 & Coupling of the $\mathrm{C}-\mathrm{C}$ backbone stretching with the $\mathrm{CH}_{3}$ \\
955 & rocking mode \\
1080 & Stretching vibration of the methyl group $(\mathrm{C}-\mathrm{H})$ \\
1180 & $\mathrm{C}-\mathrm{O}-\mathrm{C}$ asymmetric vibrations linked with asymmetric \\
1200 & $\mathrm{CH}_{3}$ rocking vibrations \\
1210 & \\
1450 & Stretching vibration of the methyl group $(\mathrm{C}-\mathrm{H})$ \\
1750 & Stretching vibration of ester carbonyl $(\mathrm{C}=\mathrm{O})$ \\
\hline
\end{tabular}

Solvent evaporation during the emulsification process of PLLA droplets can affect the degree of crystallinity of the polymer, together with other characteristics such as surface morphology and porosity features [35]. Pristine PLLA microspheres showed a glass transition around $55^{\circ} \mathrm{C}$ and a melting transition that starts at $\sim 120^{\circ} \mathrm{C}$ and ends at $\sim 160{ }^{\circ} \mathrm{C}$ with maximum at $152{ }^{\circ} \mathrm{C}$, with absence of a cold-crystallization process (Fig. 3b). With respect to the composite spheres, a shift towards higher temperatures was observed for the $\mathrm{Tg}$ and melting transition, indicating that the $\mathrm{CoFe}_{2} \mathrm{O}_{4}$ filler acts as nucleation agent for PLLA crystallization due to strong interfacial interactions with the crystallizing polymer. Thus, the incorporation of the magnetic particles increases the thermal stability of microspheres crystalline phase [36] in the vicinity of the nanoparticles. Further, a cold crystallization process starting at $\sim 80^{\circ} \mathrm{C}$ up to $\sim 130^{\circ} \mathrm{C}$, with maximum at $\sim 110^{\circ} \mathrm{C}$ was observed after the glass transition process as the temperature increased. The presence of a shoulder during melting of the polymer for nanocomposite microspheres is also observed, which can be attributed to the different crystal sizes present in the samples: ones formed during the processing of the nanocomposite polymer spheres, made from fragmented crystals, at lower temperature; and ones due to the cold-recrystallization process that takes place during the heating scan itself, at the higher temperature. The fact that cold crystallization appears only $30^{\circ} \mathrm{C}$ above the glass transition indicates that a large number of crystal nuclei had already been formed in the glass [37]. A second heating scan was recorded after cooling the sample from $200{ }^{\circ} \mathrm{C}$ to room temperature. Interestingly, after this process, the sample showed a single broad endothermic peak melting temperature, suggesting that the double melting peak is due to the presence of small nuclei in the polymer that starts to reorganize and crystallize at temperatures above $\mathrm{Tg}$ during heating (Fig. 3b).

The degree of crystallinity of neat and magnetic microspheres was calculated applying Eq. (1) and a value of $40 \%$ and $17 \%$ was obtained for pristine and magnetic nanocomposite spheres: the difference in the degree of crystallinity is attributed to the interfacial electrostatic interaction between magnetic nanoparticles and the PLLA polymer chains [38]. These strong interfacial interactions can, on the one hand, provide stability to the crystalline phase in the vicinity of the nanofillers, as they act as nucleating agents during the crystallization process. On the other hand, the presence of the nanofillers lead to an overall decrease of the degree of crystallinity as the presence of the fillers lead to larger amounts of crystallization sites, hindering the crystallization process, spherulitic growth originated in different nucleation sites and proper molecular packing [36,39].

Zeta $(\zeta)$ potential was used to characterize the surface of the PLLA microspheres at different pHs environments. This method is also an important factor for determining the stability of PLLA and nanocomposite microspheres against aggregation, when dispersed in a liquid such as the cell culture media [40]. Generally, the stability of the microspheres in suspension improves with increasing absolute values of zeta potential, moreover higher stabilities are usual obtained for values higher than $|-30| \mathrm{mV}$ [41]. Polymer surface microspheres are negatively charged and the surface charge increases with increasing pH (Fig. 4).

The negative charge of the microspheres is attributed to the presence of ionized carboxyl groups from lactic acid on particles surface [22], leading the particles to be quite stable in alkaline environments, while for more acidic environments $(\mathrm{pH} \leqslant 4)$ the spheres show a trend to aggregate, forming clusters (Fig. 4). It was observed that for a $\mathrm{pH}$ higher than 5 with a zeta potential of approximately $-30 \mathrm{mV}$, the stability of the neat PLLA spheres

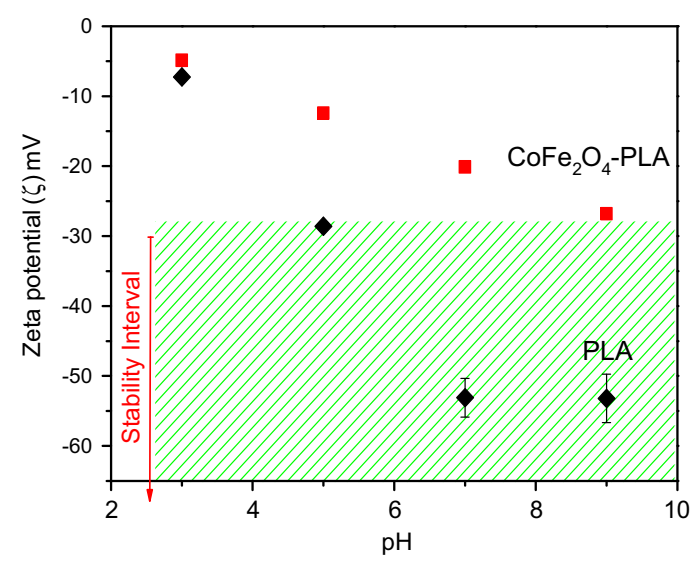

Fig. 4. Zeta potential results at different $\mathrm{pH}$ for (a) neat PLLA microspheres and (b) magnetic PLLA microspheres. 
increases and a stable colloidal dispersion is obtained. This fact can be explained due to the higher repulsion of the PLLA spheres hindering its aggregation. At $\mathrm{pH} 7.4$, the PLLA microspheres show a larger zeta potential and high negative values $(-53 \mathrm{mV})$ are obtained. It is notice that similar results were reported in the literature for PLA and for PLGA nanospheres in neutral buffer [21], with zeta potential of -50 and $-45 \mathrm{mV}$, respectively. The results also indicate that the PLLA microspheres produced by the oil in water method exhibit sensitivity to $\mathrm{pH}$ changes. This can be relevant for drug delivery applications with focus on the design and development of carriers for therapeutic and/or diagnostic purpose and also for in vivo applications and drug attachment [40]. The high zeta potential values obtained also indicate that the oil in water method does not result in a high adsorption of PVA in the surface of the microspheres. With respect to the composite microspheres, they show lower zeta potential absolute values comparatively to neat PLLA microspheres, which may be ascribed to the presence of a small amount of $\mathrm{CoFe}_{2} \mathrm{O}_{4}$ nanoparticles/clusters on the surface of the microspheres, changing the electrophoretic behavior of the microspheres in solution.

\subsection{Magnetic properties of the magnetic nanocomposite microspheres}

The magnetic properties of the composite microspheres are critical for biomedical applications [42]. The magnetization curves of magnetic microspheres determined by VSM technique at room temperature are shown in Fig. 5. Results show that the magnetization of the magnetic microspheres increase with increasing magnetic field until gradually reaches saturation. Large magnetic microspheres may have a bigger magnetic core compared to smaller ones and consequently, the saturated magnetization is higher (Fig. 5). After the maximum magnetization value, the magnetization decreases due to diamagnetic PLLA polymer [43], which acquires a magnetization in the opposite direction that applied field, leading to a decrease of the total magnetization of the composite.

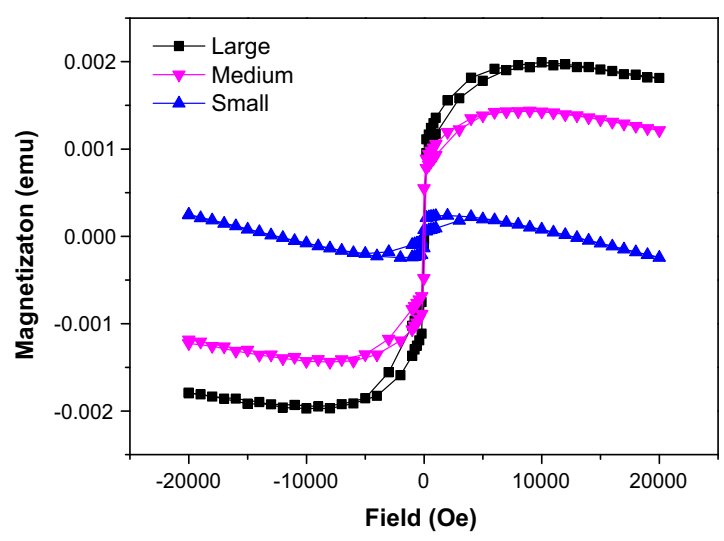

Fig. 5. Magnetization curves of the magnetic PLLA microspheres.
The shape and magnetization maximum values of the measured hysteresis loops demonstrate that magnetic nanoparticles are randomly oriented within the polymer sphere matrix.

Additionally from the hysteresis curves of Fig. 5 and the saturation magnetization value of the pure $\mathrm{CoFe}_{2} \mathrm{O}_{4}$ nanoparticles [16] it is possible to estimate, trough Eq. (3), the amount of $\mathrm{CoFe}_{2} \mathrm{O}_{4}$ nanoparticles within the microspheres (Table 2).

In this way, the concentration of $\mathrm{CoFe}_{2} \mathrm{O}_{4}$ nanoparticles in the spheres is lower than the one added to the composite solution, the loading efficiency being $\sim 40 \%$, in good agreement with previous studies [16,44], one possible explanation for this effect is the higher density of the $\mathrm{CoFe}_{2} \mathrm{O}_{4}$ nanoparticles when compared to the polymer matrix that might cause some sedimentation of nanoparticles in the solution during the microsphere formation. Further, it is to notice that the filler weight content within the microspheres is the same, independently of the sphere size, indicating a homogeneous distribution of the nanoparticles in the solution.

The magnetic properties of the magnetic microspheres and the high magnetostriction of $\mathrm{CoFe}_{2} \mathrm{O}_{4}$ nanoparticles [45] make such microspheres suitable for drug-delivery platforms with magnetically triggered drug released as well as for scaffolds with magnomechanical stimulation for tissue engineering applications [11].

\subsection{Cell culture}

In this study, the biocompatibility of PLLA microspheres with and without magnetic nanoparticles was performed. PLLA is a biocompatible polymer, but the $\mathrm{CoFe}_{2} \mathrm{O}_{4}$ particles are cytotoxic [46]. On the other hand, these particles can be "encapsulated" in a polymer in order to achieve a biocompatible magnetic composite [47]. In this way, one of the objectives in this study was to verify if these magnetic particles were properly encapsulated in the PLLA spheres.

The viability of MC3T3-E1 pre-osteoblast cells seeded in an Eppendorf with and without PLLA microspheres was performed by MTS assay and the results are shown in Fig. 6 . It is observed that

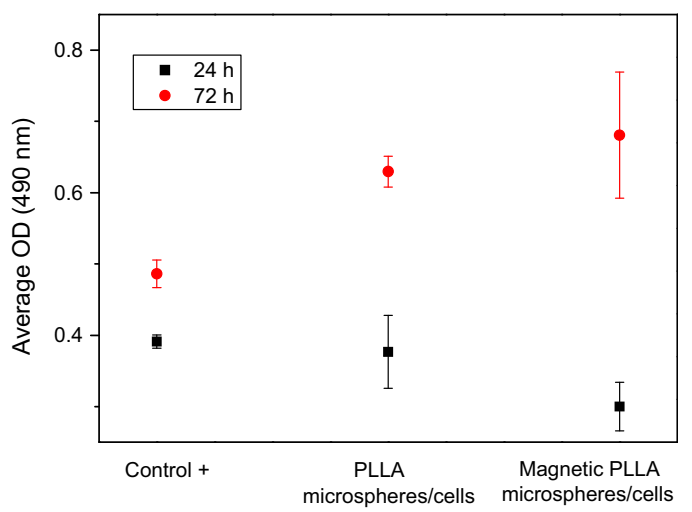

Fig. 6. MTS results from proliferation assay of PLLA microspheres (with and without magnetic nanoparticles)/cells and cells pellets (control +). Results are expressed as mean \pm standard deviation with $n=4$.

Table 2

Size, wt/wt\% and magnetization of PLLA microspheres.

\begin{tabular}{|c|c|c|c|c|c|}
\hline $\begin{array}{l}\text { Microspheres } \\
\text { size }(\mu \mathrm{m})\end{array}$ & $\begin{array}{l}\mathrm{CoFe}_{2} \mathrm{O}_{4} \mathrm{wt} / \mathrm{wt} \% \text { in the } \\
\text { solution }\end{array}$ & $\begin{array}{l}\mathrm{CoFe}_{2} \mathrm{O}_{4}+\text { PLLA } \\
\mathrm{w} / \mathrm{w}(\mathrm{g})\end{array}$ & $\begin{array}{l}\text { Spheres saturation magnetization } \\
\text { (measured) }\left(\mathrm{emu} \mathrm{g}^{-1}\right)\end{array}$ & $\begin{array}{l}\mathrm{CoFe}_{2} \mathrm{O}_{4} \text { weight in } \\
\text { microspheres }(\mathrm{g})\end{array}$ & $\begin{array}{l}\mathrm{CoFe}_{2} \mathrm{O}_{4}(\mathrm{wt} / \mathrm{wt} \%) \text { in } \\
\text { microspheres }\end{array}$ \\
\hline $\begin{array}{l}\text { Small } \\
\qquad(0.87 \pm 0.35)\end{array}$ & 10 & $1.0 \times 10^{-4}$ & $2.40 \times 10^{-4}$ & $4.0 \times 10^{-6}$ & 4.0 \\
\hline $\begin{array}{l}\text { Medium } \\
\qquad(1.6 \pm 0.6)\end{array}$ & & $6.0 \times 10^{-4}$ & $1.43 \times 10^{-3}$ & $2.38 \times 10^{-5}$ & 4.0 \\
\hline Large $(2.2 \pm 0.6)$ & & $8.0 \times 10^{-4}$ & $1.99 \times 10^{-3}$ & $3.32 \times 10^{-5}$ & 4.1 \\
\hline
\end{tabular}


the cell agglomerates are viable for all the conditions. At $72 \mathrm{~h}$, it was verified the formation of a cell/microspheres pellet in the bottom of the Eppendorf (data not shown) as verified in a previous study [2] with PVDF microspheres.

Comparing PLLA microspheres/cells pellet with the cell pellet it is verified a higher number of cells after $72 \mathrm{~h}$ of cell culture. It should be noted that MTS of negative control (only microspheres) was performed (data not shown) and no effect on absorbance measured was obtained. These preliminary results suggest that PLLA microspheres with and without magnetic nanoparticles can provide a suitable environment for cell adhesion and growth.

\section{Conclusions}

As a new platform for biomedical applications, the present work reports on the preparation and size separation of neat and cobalt ferrite magnetic composite PLLA based microspheres by a single emulsion method, using chloroform as solvent and PVA as a stabilizer. The diameters of the microspheres after processing range between 0.16 and $3.9 \mu \mathrm{m}$ for neat PLLA and between 0.8 and $2.2 \mu \mathrm{m}$ for the composite microspheres. Further, the microspheres were separated by size by centrifugation.

Both neat and magnetic PLLA show a glass transition temperature around $55^{\circ} \mathrm{C}$, with double melting peaks. The degree of crystallinity of the neat PLLA microspheres is $40 \%$ after processing and the incorporation of the $\mathrm{CoFe}_{2} \mathrm{O}_{4}$ nanoparticles into the PLLA sample leads to nearly amorphous magnetic microspheres. The encapsulation efficiency of the magnetic nanoparticles is $40 \%$, independently of the particle size. Finally, both neat and magnetic microspheres are quite stable in alkaline environments, however, for more acidic environments $(\mathrm{pH} \leqslant 4)$, the neat PLLA microspheres aggregate, forming clusters.

Cell viability studies performed with MC3T3-E1 pre-osteoblast cells showed proper cell proliferation, which demonstrates the encapsulation of the cobalt ferrite nanoparticles and the suitability of the microspheres for biomedical applications such as drug delivery systems and tissue engineering.

\section{Acknowledgments}

This work is funded by FCT - Fundação para a Ciência e a Tecnologia, grants SFRH/BD/82411/2011 (DMC), SFRH/ BPD/90870/2012 (CR), SFRH/BD/98616/2013 (PMM) and SFRH/ $\mathrm{BPD} / 97739 / 2013$ (PM), respectively. The authors thank support from the COST Action MP1206 "Electrospun Nano-fibres for bio inspired composite materials and innovative industrial applications" and from the Basque Government Industry Department under the ELKARTEK Program. SLM thanks the Diputación Foral de Bizkaia for financial support under the Bizkaia Talent Programme; European Union's Seventh Framework Programme; Marie Curie Actions-People; Grant agreement no. 267230.

\section{References}

[1] E.K. Efthimiadou, L.A. Tziveleka, P. Bilalis, G. Kordas, Novel PLA modification of organic microcontainers based on ring opening polymerization: synthesis, characterization, biocompatibility and drug loading/release properties, Int. J. Pharm. 428 (2012) 134-142.

[2] D.M. Correia, R. Gonçalves, C. Ribeiro, V. Sencadas, G. Botelho, J.L. Gomez Ribelles, S. Lanceros-Méndez, Electrosprayed poly(vinylidene fluoride) microparticles for tissue engineering applications, RSC Adv. 4 (2014) 3301333021.

[3] P. Martins, A.C. Lopes, S. Lanceros-Mendez, Electroactive phases of poly (vinylidene fluoride): determination, processing and applications, Prog. Polym. Sci. 39 (2014) 683-706.

[4] J.C. Dias, C. Ribeiro, V. Sencadas, G. Botelho, J.L. Gómez-Ribelles, S. LancerosMendez, Influence of fiber diameter and crystallinity on the stability of electrospun poly(L-lactic acid) membranes to hydrolytic degradation, Polym. Test. 31 (2012) 770-776.
[5] J. Pärssinen, H. Hammarén, R. Rahikainen, V. Sencadas, C. Ribeiro, S. Vanhatupa, S. Miettinen, S. Lanceros-Méndez, V.P. Hytönen, Enhancement of adhesion and promotion of osteogenic differentiation of human adipose stem cells by poled electroactive poly(vinylidene fluoride), J. Biomed. Mater. Res. A 103 (2015) 919-928.

[6] C. Ribeiro, V. Sencadas, D.M. Correia, S. Lanceros-Méndez, Piezoelectric polymers as biomaterials for tissue engineering applications, Colloids Surf. B 136 (2015) 46-55.

[7] X. Zhang, L. Xue, J. Wang, Q. Liu, J. Liu, Z. Gao, W. Yang, Effects of surface modification on the properties of magnetic nanoparticles/PLA composite drug carriers and in vitro controlled release study, Colloids Surf. A 431 (2013) 8086.

[8] S. Munjal, N. Khare, C. Nehate, V. Koul, Water dispersible $\mathrm{CoFe}_{2} \mathrm{O}_{4}$ nanoparticles with improved colloidal stability for biomedical applications, J. Magn. Magn. Mater. 404 (2016) 166-169.

[9] P. Martins, S. Lanceros-Méndez, Polymer-based magnetoelectric materials, Adv. Funct. Mater. 23 (2013) 3371-3385.

[10] V. Závišová, M. Koneracká, M. Múčková, P. Kopčanský, N. Tomašovičová, G. Lancz, M. Timko, B. Pätoprstá, P. Bartoš, M. Fabián, Synthesis and characterization of polymeric nanospheres loaded with the anticancer drug paclitaxel and magnetic particles, J. Magn. Magn. Mater. 321 (2009) 16131616.

[11] C. Ribeiro, V. Correia, P. Martins, F.M. Gama, S. Lanceros-Mendez, Proving the suitability of magnetoelectric stimuli for tissue engineering applications, Colloids Surf. B 140 (2016) 430-436.

[12] S.J. Lee, A.P. Arun, K.J. Kim, Piezoelectric properties of electrospun poly(L-lactic acid) nanofiber web, Mater. Lett. 148 (2015) 58-62.

[13] Y. Mitsunobu, T. Onogi, K. Onishi, T. Inagaki, Y. Tajitsu, High piezoelectric performance of poly(lactic acid) film manufactured by solid-state extrusion, Jpn. J. Appl. Phys. 53 (2014) 09PC02.

[14] R. Herrero-Vanrell, I. Bravo-Osunaa, V. Andrés-Guerrero, M. Vicario-de-laTorre, I.T. Molina-Martínez, The potential of using biodegradable microspheres in retinal diseases and other intraocular pathologies, Prog. Retin. Eye Res. 42 (2014) 27-43.

[15] Y. Gao, Y. Bai, D. Zhao, M.W. Chang, Z. Ahmad, J.S. Li, Tuning microparticle porosity during single needle electrospraying synthesis via a non-solventbased physicochemical approach, Polymers 7 (2015) 2701-2710.

[16] R. Goncalves, P. Martins, D.M. Correia, V. Sencadas, J.L. Vilas, L.M. León, G. Botelho, S. Lanceros-Méndez, Development of magnetoelectric $\mathrm{CoFe}_{2} \mathrm{O}_{4} /$ poly (vinylidene fluoride) microspheres, RSC Adv. 5 (2015) 35852-35857.

[17] J.G. Fernandes, D.M. Correia, G. Botelho, J. Padrão, F. Dourado, C. Ribeiro, S. Lanceros-Méndez, V. Sencadas, PHB-PEO electrospun fiber membranes containing chlorhexidine for drug delivery applications, Polym. Test. 34 (2014) 64-71.

[18] S. Freitas, H.P. Merkle, B. Gander, Microencapsulation by solvent extraction/ evaporation: reviewing the state of the art of microsphere preparation process technology, J. Control. Release 102 (2005) 313-332.

[19] C. Berkland, K. Kim, D.W. Pack, Fabrication of PLG microspheres with precisely controlled and monodisperse size distributions, J. Control. Release 73 (2001) 59-74.

[20] K. Kim, D. Pack, Microspheres for drug delivery, in: M. Ferrari, A. Lee, L.J. Lee (Eds.), BioMEMS and Biomedical Nanotechnology, Springer, 2006, pp. 19-50.

[21] S.K. Sahoo, J. Panyam, S. Prabha, V. Labhasetwar, Residual polyvinyl alcohol associated with poly (D, L-lactide-co-glycolide) nanoparticles affects their physical properties and cellular uptake, J. Control. Release 82 (2002) 105-114.

[22] G. Ruan, S.-S. Feng, Preparation and characterization of poly(lactic acid)-poly (ethylene glycol)-poly(lactic acid) (PLA-PEG-PLA) microspheres for controlled release of paclitaxel, Biomaterials 24 (2003) 5037-5044.

[23] F. Li, X. Li, B. Li, Preparation of magnetic polylactic acid microspheres and investigation of its releasing property for loading curcumin, J. Magn. Magn, Mater. 323 (2011) 2770-2775.

[24] L.B. Silveira, J.G. Santos, A.C. Oliveira, A.C. Tedesco, J.M. Marchetti, E.C.D. Lima, P.C. Morais, Susceptibility of cobalt ferrite nanoparticles dispersed in polylactic acid microspheres, J. Magn. Magn. Mater. 272-276 (2004) e1195e1196.

[25] Nanostructured \& Amorphous Materials, Inc. in http://www.nanoamor.com/ inc/sdetail/3968.

[26] M.N. Freitas, J.M. Marchetti, Nimesulide PLA microspheres as a potential sustained release system for the treatment of inflammatory diseases, Int. J. Pharm. 295 (2005) 201-211.

[27] L. Francis, D. Meng, J. Knowles, T. Keshavarz, A.R. Boccaccini, I. Roy, Controlled delivery of gentamicin using poly(3-hydroxybutyrate) microspheres, Int. J. Mol. Sci. 12 (2011) 4294-4314.

[28] C. Ribeiro, V. Sencadas, C.M. Costa, J.L. Gómez Ribelles, S. Lanceros-Méndez, Tailoring the morphology and crystallinity of poly(L-lactide acid) electrospun membranes, Sci. Technol. Adv. Mater. 12 (2011) 015001.

[29] S. Jain, M. Misra, A.K. Mohanty, A.K. Ghosh, Thermal, mechanical and rheological behavior of poly(lactic acid)/talc composites, J. Polym. Environ. 20 (2012) 1027-1037.

[30] W.J. Lau, A.F. Ismail, P.S. Goh, N. Hilal, B.S. Ooi, Characterization methods of thin film composite nanofiltration membranes, Sep. Purif. Rev. 44 (2014) 135156.

[31] S. Freiberg, X.X. Zhu, Polymer microspheres for controlled drug release, Int. J. Pharm. 282 (2004) 1-18.

[32] R. Gonçalves, P.M. Martins, C. Caparrós, P. Martins, M. Benelmekki, G. Botelho, S. Lanceros-Mendez, A. Lasheras, J. Gutiérrez, J.M. Barandiarán, Nucleation of 
the electroactive $\beta$-phase, dielectric and magnetic response of poly(vinylidene fluoride) composites with $\mathrm{Fe}_{2} \mathrm{O}_{3}$ nanoparticles, J. Non-Cryst. Solids 361 (2013) 93-99.

[33] V. Krikorian, D.J. Pochan, Crystallization behavior of poly(L-lactic acid) nanocomposites: nucleation and growth probed by infrared spectroscopy, Macromolecules 38 (2005) 6520-6527.

[34] T. Furukawa, H. Sato, R. Murakami, J. Zhang, Y.-X. Duan, I. Noda, S. Ochiai, Y. Ozaki, Structure, dispersibility, and crystallinity of poly(hydroxybutyrate)/ poly(L-lactic acid) blends studied by FT-IR microspectroscopy and differential scanning calorimetry, Macromolecules 38 (2005) 6445-6454.

[35] T.-W. Chung, Y.-Y. Huang, Y.-Z. Liu, Effects of the rate of solvent evaporation on the characteristics of drug loaded PLLA and PDLLA microspheres, Int. J. Pharm. 212 (2001) 161-169.

[36] V. Sencadas, P. Martins, A. Pitães, M. Benelmekki, J.L. Gómez Ribelles, S. Lanceros-Mendez, Influence of ferrite nanoparticle type and content on the crystallization kinetics and electroactive phase nucleation of poly(vinylidene fluoride), Langmuir 27 (2011) 7241-7249.

[37] V. Sencadas, C.M. Costa, G. Botelho, C. Caparrós, C. Ribeiro, J.L. Gómez-Ribelles, S. Lanceros-Mendez, Thermal properties of electrospun poly(lactic acid) membranes, J. Macromol. Sci. B 51 (2011) 411-424.

[38] P. Martins, C.M. Costa, M. Benelmekki, G. Botelho, S. Lanceros-Mendez, On the origin of the electroactive poly(vinylidene fluoride) $\beta$-phase nucleation by ferrite nanoparticles via surface electrostatic interactions, CrystEngComm 14 (2012) 2807-2811.

[39] A.C. Lopes, C.M. Costa, C.J. Tavares, I.C. Neves, S. Lanceros-Mendez, Nucleation of the electroactive $\gamma$ phase and enhancement of the optical transparency in low filler content poly(vinylidene)/clay nanocomposites, J. Phys. Chem. C 115 (2011) 18076-18082.

[40] D. Moorkoth, K. Nampoothiri, Synthesis, colloidal properties and cytotoxicity of biopolymer nanoparticles, Appl. Biochem. Biotechnol. 174 (2014) 21812194.

[41] W. Wang, S. Chen, L. Zhang, X. Wu, J. Wang, J.F. Chen, Y. Le, Poly(lactic acid)/chitosan hybrid nanoparticles for controlled release of anticancer drug, Mater. Sci. Eng. C 46 (2015) 514-520.

[42] N. Tran, T.J. Webster, Magnetic nanoparticles: biomedical applications and challenges, J. Mater. Chem. 20 (2010) 8760-8767.

43] L. Garrido, Magnetic orientation of diamagnetic amorphous polymers, J. Polym. Sci. B 48 (2010) 1009-1015.

[44] R. Goncalves, P. Martins, X. Moya, M. Ghidini, V. Sencadas, G. Botelho, N.D. Mathur, S. Lanceros-Mendez, Magnetoelectric $\mathrm{CoFe}_{2} \mathrm{O}_{4} /$ polyvinylidene fluoride electrospun nanofibres, Nanoscale 7 (2015) 8058-8061.

[45] P. Martins, A. Lasheras, J. Gutierrez, J.M. Barandiaran, I. Orue, S. LancerosMendez, Optimizing piezoelectric and magnetoelectric responses on $\mathrm{CoFe}_{2} \mathrm{O}_{4} /$ P(VDF-TrFE) nanocomposites, J. Phys. D 44 (2011) 495303-495309.

[46] P.K. Prabhakar, S. Vijayaraghavan, J. Philip, M. Doble, Biocompatibility studies of functionalized $\mathrm{CoFe}_{2} \mathrm{O}_{4}$ magnetic nanoparticles, Curr. Nanosci. 7 (2011) 371-376.

[47] R. Costa, C. Ribeiro, A.C. Lopes, P. Martins, V. Sencadas, R. Soares, S. LancerosMendez, Osteoblast, fibroblast and in vivo biological response to poly (vinylidene fluoride) based composite materials, J. Mater. Sci. Mater. Med. 24 (2013) 395-403. 